\title{
Vasodilator response to Psidium guajave leaves of mesenteric bed vessels from diabetic and non-diabetic rats
}

\author{
Habeib Zaheri ${ }^{1}$, Golam Reza Farshidfar ${ }^{2}$, Nepton Soltani ${ }^{3^{*}}$, Fatemah Kharazmi ${ }^{3}$, \\ Mohammad Kamalinajad ${ }^{4}$ \\ ${ }^{1}$ Department of Biology, Faculty of Science, Shahid Bahonar University, Kermam, Iran \\ ${ }^{2}$ Department of Biochemistery, Faculty of Medicine, Hormozgan University of Medical Sciences, Bandar Abbas, Iran \\ ${ }^{3}$ Department of Physiology, Faculty of Medicine, and Research Center for Molecular Medicine Hormozgan University of Medical \\ Sciences, Bandar Abbas, Iran; ${ }^{*}$ Corresponding Author: solnep2002@yahoo.com, nsoltani@hums.ac.ir \\ ${ }^{4}$ Department of Pharmacognosy, Faculty of Pharmacy, Shahid Bahashti University of Medical Sciences, Tehran, Iran
}

Received 11 November 2013; revised 10 December 2013; accepted 18 December 2013

Copyright (C) 2014 Habeib Zaheri et al. This is an open access article distributed under the Creative Commons Attribution License, which permits unrestricted use, distribution, and reproduction in any medium, provided the original work is properly cited. In accordance of the Creative Commons Attribution License all Copyrights (C) 2014 are reserved for SCIRP and the owner of the intellectual property Habeib Zaheri et al. All Copyright (c) 2014 are guarded by law and by SCIRP as a guardian.

\section{ABSTRACT}

Mortality from cardiovascular abnormalities is almost three times more prevalent in the diabetic population than that in the general population. Psidium guajave has been used traditionally for a long time as a medicinal herb to cure diabetes. Endothelial dependent vasorelaxation effect of Psidium guajave extract on normal aortic rings was observed. This study was designed to investigate the endothelium and nitric oxide roles in PGE-induced vasorelaxation in diabetic rat vessel. Diabetes was induced by a single intraperitoneal injection of streptozotocin. Eight weeks later, superior mesenteric arteries of non-diabetic and diabetic groups were isolated and perfused according to the McGregor method. Prepared vascular beds were constricted with phenylephrine to induce $70 \%-75 \%$ of maximal constriction. Psidium guajave extract at concentrations of 0.1 to 4 $\mathrm{mg} / 100 \mathrm{ml}$ added to the medium and perfusion pressure was recorded. Baseline perfusion pressure of diabetic group was significantly higher than non-diabetic rats in both intact and denuded endothelium. Psidium guajave extract caused a significantly dose depended decrease in perfusion pressure in non-diabetic and diabetic groups in both intact and denuded endothelium. In the presence of $N(\omega)$-nitro-L-arginine methyl ester, Psidium guajave ex-tract- induced relaxation in intact mesenteric beds of non-diabetic and diabetic animals was not suppressed. From the results of this study, it may be concluded that vasorelaxatory effect of Psidium guajave extract is not mediated by endothelium and nitric oxide in both diabetic and non-diabetic vessel and supports the use of the plant's leaves as a natural, adjunct phytomedicine in the management of diabetes vessel complications.

\section{KEYWORDS}

Psidium guajave Linn Extract; Diabetes Mellitus; Mesenteric Bed; Vasorelaxation; Nitric Oxide

\section{INTRODUCTION}

Cardiovascular disorders continue to constitute major causes of morbidity and mortality in spite of significant achievement made over the past decades in the diagnosis and treatment of these conditions [1,2]. Mortality from cardiovascular abnormalities, including hypertension, atherosclerosis, microangiopathy, and congestive heart failure, is almost three times more prevalent in the diabetic population than that in the general population $[3,4]$. Although the etiology of vascular disorders in diabetes has not completely been understood, it is suggested that the high incidence of vascular atherosclerosis and poor control of hyperglycemia appear to play a significant role in the development of cardiovascular disease in diabetes 
[5]. Recently, there has been increasing evidence regarding the fact that the postprandial state is an important contributing factor to the development of atherosclerosis [5]. Endothelial function is altered early in diabetes. It has been demonstrated that in diabetic subjects, the vasodilating response to stimuli is diminished and that this anomaly is related to glycemic control [6]. In vivo studies demonstrated that hyperglycemic spikes induce, in both diabetic and normal subjects, an endothelial dysfunction [2,7]. This effect of hyperglycemia is probably linked with a reduced production/bioavailability of nitric oxide (NO), since hyperglycemia-induced endothelial dysfunction is counterbalanced by arginine [2].

The leaf of Psidium guajave is used traditionally in Asia to manage, control and treat diabetes. Guava has been traditionally used for a long time as a medicinal herb to cure diabetes mellitus. Many people in some countries/ areas including Japan, Taiwan and Iran boil guajave leaves in water and drink the extract as an ancient medicine for diabetes and hypertension [8]. In our pervious study, we showed that the administration of Psidium guajave Linn extract (PGE) in diabetic rats caused $\mathrm{Ca} / \mathrm{Mg}$ ratio, plasma glucose, lipid profiles to return to the normal levels, and was shown to decrease alteration in vascular reactivity to vasoconstrictor agents [9]. Some researchers have observed endothelial dependent vasorelaxation effect of Psidium guajave on normal aortic rings $[8,10]$, but there is no more information about the effect of Psidium guajave on diabetic vessel. This study was designed to investigate the endothelium and nitric oxide roles in PGE-induced vasorelaxation in diabetic rat vessel.

\section{MATERIAL AND METHODS}

\subsection{Animals}

The animals were handled in based on with the criteria outlined in the "Guide for Care and Use of Laboratory Animals" (NIH US publication 86-23 revised 1985).

Locally produced Male rats (body weight 180 - 250 gr) were used. All animals were maintained at a constant temperature $\left(23^{\circ} \mathrm{C} \pm 2^{\circ} \mathrm{C}\right)$ with a fixed 12 : 12-h light-dark cycle. Animals were divided into six groups $(n=6$ in each group): three diabetics and three non- diabetics kept in animal room for eight weeks. Animals were monitored for blood glucose concentrations and body weight every week. Blood glucose was measured with an Ascensia ELITE XL glucometer and Ascensia Elite blood glucose test strips.

\subsection{Diabetes Induction}

Diabetes was produced with single intraperitoneal injection of STZ (60 mg/kg). Ten days after STZ injection, blood glucose levels were determined using a glucometer (Ascensia ELITE XL glucometer). Rats with blood glu- cose levels of $250 \mathrm{mg} / \mathrm{dl}$ were considered to be diabetic.

\subsection{Preparation of guajave Leaf Extracts}

Fresh leaves of Psidium guajave were collected from open grassland in Minab (Southern Iran). The plant was identified by the Taxonomist at Shahid Bahashti University of Medical Science. One kilogram of fresh Psidium guajave leaves was air dried under shade at room temperature $\left(26^{\circ} \mathrm{C} \pm 1^{\circ} \mathrm{C}\right)$ for 2 weeks. The dried leaves were then milled into a fine powder in Waring commercial blender. The powdered leaves were extracted with deionized water followed by 15 minutes of boiling under continuous stirring. The extract was filtered through filter paper (Whatman No 1). The dry weight in the extract was evaluated in samples dried at $80^{\circ} \mathrm{C}$ until constant weight. The percentage yields based on the dried starting material was $21 \%$ for dried aqueous. The concentrated extracts and fractions as stock were stored at $-20^{\circ} \mathrm{C}$ in a desiccant before use [11].

\subsection{Preparation of Extracts and Fractions}

To obtain the aqueous extract (Aq. E), $44 \mathrm{~g}$ of the ground plant material was macerated using $1500 \mathrm{ml}$ of deionized water followed by 15 minutes of boiling under continuous stirring. The extracting was followed by rapid filtration through a crude cellulose filter and then by a more delicate filtration through Whatman No. 1 filter. E. The dry weight in the extract was evaluated in samples dried at $80^{\circ} \mathrm{C}$ until constant weight. The percentage yields based on the dried starting material was $21 \%$ for dried Aq. The concentrated extracts and fractions as stock were stored at $-20^{\circ} \mathrm{C}$ in a desiccant until require.

\subsection{GC/MS Analysis}

GC/MS analysis of aqueous extract was performed on a mass spectrometer connected to a gas chromatography system (GC/MSD) 7890A, 7000 Triple Quad series Agilent, which was equipped with a HP-5MS capillary column $(30 \mathrm{~m} \times 0.25 \mathrm{~mm}$; film thickness of $0.2 \overline{\mathrm{pm}})$. H elium was used as carrier gas at a rate flow of $1 \mathrm{ml} / \mathrm{min}$. The GC oven temperature was programmed from $50^{\circ} \mathrm{C}$ to $260^{\circ} \mathrm{C}$ at a rate of $10^{\circ} / \mathrm{min}$ and kept at $260^{\circ} \mathrm{C}$ for 26 min. MS was performed at 1 scan s- 1 with ionizing voltage of $70 \mathrm{~V}$ and ion source temp. of $280^{\circ} \mathrm{C}$. Separated compounds were identified by comparing their retention times with those of authentic standards injected under the same chromatographic conditions and by comparison of their retention indices and their mass spectra of the unknown peaks with the MS Library.

\subsection{Preparation of Mesenteric Vascular Bed}

After eight weeks all animals were anesthetized by i.p. 
injection of ketamine $\mathrm{HCl} 50 \mathrm{mg} / \mathrm{kg}$ and the mesenteric vascular beds was prepared as originally described by McGregor [12]. In brief, abdominal wall was opened, superior mesenteric artery was exposed and cannulated, then gently flushed with modified Krebs Henseleit solution (containing in mM: $\mathrm{NaCl}: 118, \mathrm{KCl}: 4.7, \mathrm{CaCl}_{2}: 2.5$, $\mathrm{MgSO}_{4}: 1.2$, glucose: 2, $\mathrm{NaHCO}_{3}: 2.5, \mathrm{NaHPO}_{4}: 1.2$ ) concomitantly bubbled with a mixture of $95 \% \mathrm{O}_{2}$ and $5 \%$ $\mathrm{CO}_{2}$ (final $\mathrm{pH}$ 7.4), and warmed to $37^{\circ} \mathrm{C}$. The mesentery was isolated from the intestine, and placed in a waterjacked perfusion chamber maintained at $37^{\circ} \mathrm{C}$. The preparation was perfused at $1 \mathrm{ml} / \mathrm{min}$ with modified Krebs Henseleit solution by a peristaltic pump (Meredos GmbH). The tissue was prevented from drying by superfusion with $0.1 \mathrm{ml} / \mathrm{min}$ modified Krebs Henseleit solution. Perfusion pressure was monitored via a $\mathrm{T}$ tube inserted between the pump and the inflow cannula. This was connected to a pressure transducer MLT0380 ADInstruments). A Power Lab System recorded the procedure (16SP, ADInstruments). After 30-minute equilibration, the vascular bed was constricted by Krebs-Henseleit solution containing phenylephrine, an $\alpha_{1}$-adrenoceptor agonist, $(0.001 \mathrm{M}$ for intact and denuded diabetic groups and $0.003 \mathrm{M}$ for intact and denuded non-diabetic groups) to induce $70 \%-75 \%$ of maximal vasoconstriction (the doses of phenylephrine were chosen according to the phenylephrine dose response curve, data not shown in the results) then allowed to reach a plateau and stabilize. Psidium guajave leaves extract at concentrations from 0.1 to $4 \mathrm{mg} / 100 \mathrm{ml}$ added to the medium then perfusion pressure was recorded. Drug concentration was increased every 15 minutes.

\subsection{Endothelial Denudation}

To achieve endothelial denudation, the preparation was perfused with distilled water for 5 minutes [13].

\subsection{Nitric Oxide Inhibition}

To inhibit nitric oxide production, L-NAME, a non selective nitric oxide synthase (NOS) inhibitor at dose of $0.0001 \mathrm{M}$ was added to medium 20 min before phenylephrine administration. Then phenylephrine concentration was adjusted to achieve $70 \%-75 \%$ of maximum contractile response.

\subsection{Drugs}

The following drugs were used: STZ was obtained from Sigma (USA) and dissolved in $1 \mathrm{ml}$ normal saline immediately before use. Phenylephrine and L-NAME (non specific NOS synthesis inhibitor) were obtained from Sigma (St. Louis, MO, USA), ketamine $\mathrm{HCl}$ was obtained from Rotexmedica (Trittau, Germany).

\subsection{Statistical Analysis}

Data expressed as Mean \pm SEM comparisons between groups were analyzed by two-way analysis of variance followed by Tukey test, using SPSS software. $\mathrm{P}<0.05$ was considered significant.

\section{RESULTS}

No significant differences were found between groups before the intervention. Ten days after STZ injection plasma glucose levels were significantly increased from $110.67 \pm 5.17$ to $440.2 \pm 71.9 \mathrm{mg} / \mathrm{dl}$. Eight weeks after diabetes induction, plasma glucose levels remained significantly elevated in diabetic rats.

\subsection{Identification of Compounds in the Extract}

RT-1) Heptane,3-methyl-

RT-2) Cyclopentane,1-ethyl-3-methyl-

RT-4) acetic acid, butyl ester

RT-6) undecane

RT-7) Oxalic acid, isobutyl nonyl ester

RT-8) tetracosane

RT-9) 1-Iodo-2-methylundecane

The active component of the aqueous guava leaf extract is 1-Iodo-2-methylundecane.

\subsection{Mesenteric Bed Response}

Baseline perfusion pressure of diabetic group was significantly $(\mathrm{p}<0.001)$ higher than non-diabetic rats in both intact and denuded endothelium (Figure 1).

Psidium guajave leaves extract (PGE) at doses 0.1 to 4 $\mathrm{mg} / 100 \mathrm{ml}$ caused a significantly dose depended decrease in perfusion pressure in non-diabetic (Figure 2(a)) and diabetic (Figure 2(b)) groups in both intact and denuded

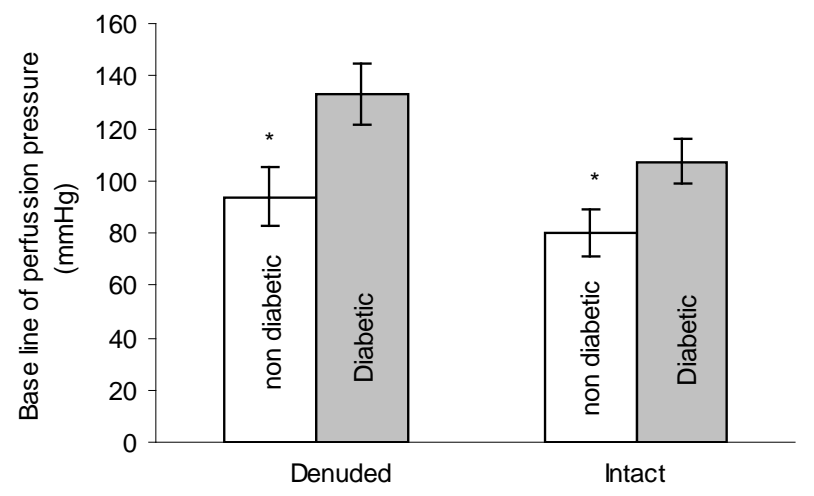

*Significant difference between diabetic and non-diabetic group with intact and denuded endothelium $(\mathrm{P}<0.001)$.

Figure 1. Baseline perfusion pressure $(\mathrm{mmHg})$ of mesenteric vascular bed in non-diabetic and diabetic group with intact and denuded endothelium (6 rats in each group). data are expressed as mean \pm SEM). 


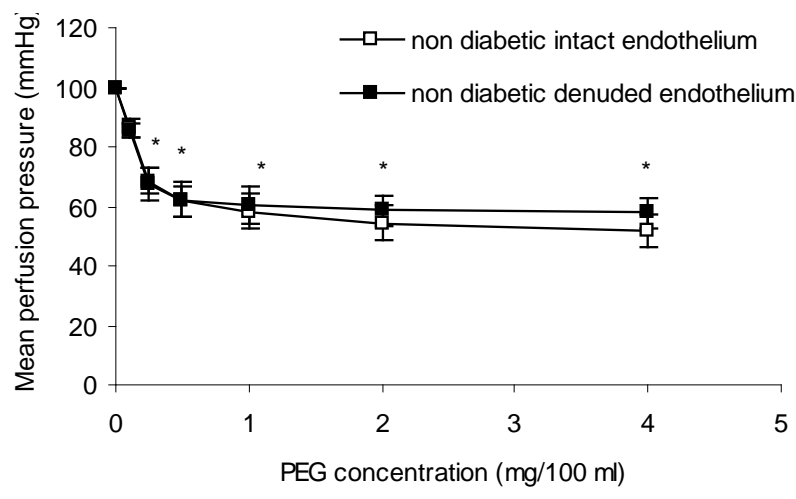

(a)

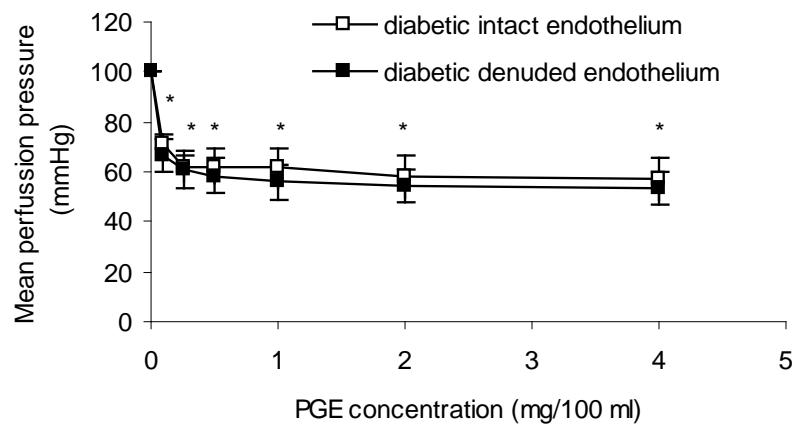

(b)

*Significant difference between response to Phenylephrine and Psidium guajave leaves extract in presence of Phenylephrine in each group $(\mathrm{P}<$ $0.001)$.

Figure 2. Dose response curves of Psidium guajave leaves extract (PGE) in mesenteric vascular bed of (a) non-diabetic and (b) diabetic animals with intact and denuded endothelium. (6 rats in each group, data were expressed as mean \pm SEM).

endothelium. The relaxatory effect of PGE was started from low dose of PGE $(0.1 \mathrm{mg} / 100 \mathrm{ml})$ and reached to the steady state at $1 \mathrm{mg} / 100 \mathrm{ml}$ dose in both non-diabetic and diabetic groups. As Figures 2(a) and (b) show, after endothelium denudation PGE decreased perfusion pressure in both groups and there was no significant differences between intact and denuded endothelium groups in both non-diabetic and diabetic animals.

In the presence of L-NAME (0.0001 M), PGE - induced relaxation in intact mesenteric beds of non-diabetic and diabetic animals was not suppressed and perfusion pressure in both groups decreased significantly (Figures 3(a) to (b)). Significant differences were observed at PGE concentration of 0.1 to $4 \mathrm{mg} / 100 \mathrm{ml}$ with the presence and absence of L-NAME in each group as compared to phenylephrine response.

\section{DISCUSSION}

This study was designed to investigate the endothelium and nitric oxide roles in PGE-induced vasorelaxation in diabetic rat vessel. The results of the present study indicate that the vasorelaxatory effect of PGE in non-

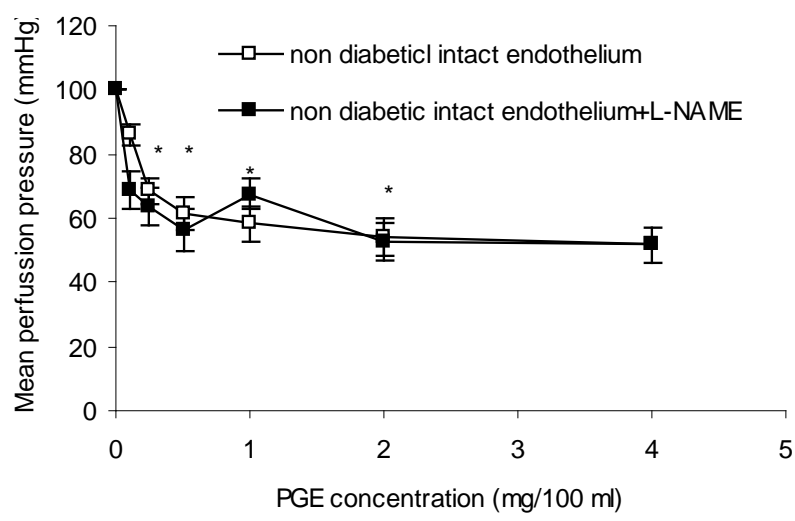

(a)

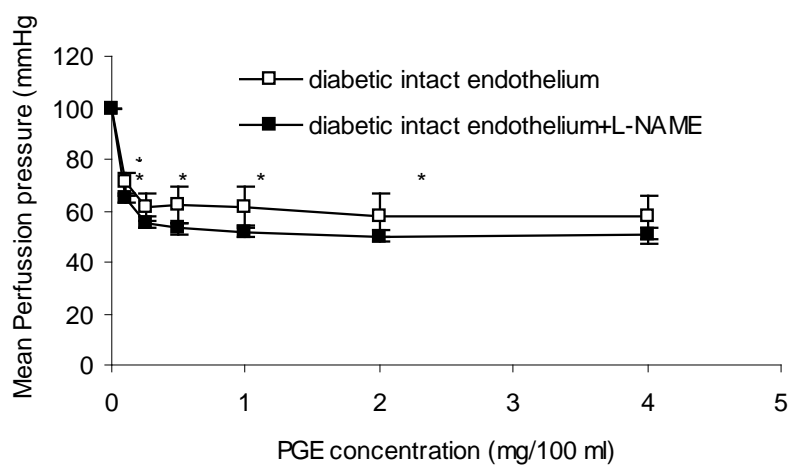

(b)

*Significant difference between response to Phenylephrine and Psidium guajave leaves extract (PGE) in presence of Phenylephrine or Phenylephrine and L-NAME in each group $(\mathrm{P}<0.001)$

Figure 3. Dose response curve of Psidium guajave leaves extract (PGE) in mesenteric vascular bed with intact endothelium in non-diabetic control (a) and diabetic (b) animals with the presence and absence of L-NAME (6 rats in each group, data expressed as Mean $\pm \mathrm{SEM}$ ).

diabetic and diabetic animals is not dependent on the endothelium and it could not be mediated by nitric oxide system.

Vascular disease is one of the complicating features of diabetes mellitus. Several prospective studies have indicated that hypertension in diabetic patients takes place at a rate more than twice of what is compared to the normal population [14]. The hypertension is also considered an independent risk factor for cardiovascular mortality in patients with diabetes [14]. In our previous studies [15, 16] we showed that the blood pressure increased eight weeks after diabetic induction in rats. We also observed that arthrosclerosis in mesenteric bed was performed eight weeks after diabetic induction in rat $[15,16]$.

As expected, in our study baseline perfusion pressure in denuded endothelium mesenteric bed in both nondiabetic and diabetic rats was higher than those with intact endothelium. This difference seems to be related to endothelial cells [17]. Baseline perfusion pressure in intact and denuded endothelium of diabetic groups was 
higher than non-diabetics. This finding is in accordance with endothelium dysfunction [18] and atherosclerosis in diabetes [19].

Four novel major findings have emerged from the present study regarding PGE: 1) low and high concentration of PGE can decrease the perfusion pressure of nondiabetic and diabetic mesentery bed vessels, so PGE must have vasodilatory effect in the diabetic subject and the effect of PGE in diabetic vessel reports for the first time in this study. Although Witness et al. showed that high concentrations of PGE (1 - $4 \mathrm{mg} / \mathrm{ml})$ produce initial brief contractions, followed by secondary, pronounced relaxations of noradranaline-contracted endotheliumintact aorta rings preparations in normal rats [9] and Olatunji-Bello et al. observed that PGE $(0.25-2 \mathrm{mg} / \mathrm{ml})$ significantly contracted normal rat isolated aortic rings in a concentration-related manner [20] 2) there is not any different effect between diabetic and non-diabetic in degrees of vasodilatory effect. We suggest PGE in two groups acts via a common pathway and diabates didn't affect it. 3) However, the previous study [9] showed that the relaxatory effect of PGE in normal group was mediated by endothelium but in this study, the relaxatory effect of PGE in diabetic and non-diabetic groups is not mediated by endothelium, so PGE has direct action on the smooth muscle. 4) Although the previous study [9] has showed the relaxatory effect of PGE in normal vessel mediated by nitric oxide, in the present study we showed that the relaxatory effect of PGE in diabetic and non-diabetic groups is not mediated by nitric oxide.

Wintness et al. have reported that PGE contains many flavonoids [9]. Some studies suggested that the vascular beneficial effects of flavonoids are closely related to their free radical scavenging and antioxidant properties, which might thus protect NO from superoxide-induced inactivation [21]. But in this study, it is not unreasonable to speculate that the primary mechanism of PGE or flavonoid-induced vasodilation results from production of NO. Protein kinase C (PKC) has been proposed to play a key role in the maintenance of tonic contractions of vascular smooth muscles [22]. PKC from a rat brain was inhibited by plant flavonoids in a concentration-dependent manner, depending on the flavonoid's structure [23]. Duarte et al. have shown that the vasoconstriction induced by PKC activator was inhibited by flavonoids in the rat aorta $[24,25]$. From these studies and our results, it is reasonable to understand that the vasorelaxatory effect of PGE is mediated by inhibition of protein kinases, such as myosin light chain kinase, and possibly, other kinases involved in Ca-sensitizing mechanisms, including PKC.

In fact, endothelial dysfunction and nitric oxide reduction have been observed in diabetes, so finding non-endothelial dependent vasorelaxation medication is very important. Our results have shown that PGE could de- crease diabetic vessel resistance independent of endothelium and nitric oxide.

From the results of this study it may be concluded that vasorelaxatory effect of PGE could not be mediated by endothelium and nitric oxide in both diabetic and non-diabetic vessel and supported the use of the plant's leaves as a natural, adjunct phytomedicine in the management of diabetes vessel complications in future.

\section{ACKNOWLEDGMENT}

This research is supported by the Deputy of Research of Hormozgan University of Medical Sciences and Mr. Hamid Mahmoodi member of faculty, English M.A, department of English in nursing faculty improved the use of English in the manuscript.

\section{REFERENCES}

[1] Stamler, J., Vaccaro, O., Neaton, J.D. and Wentworth, D. (1993) The multiple risk factor intervention trial research group, diabetes, other risk factors and 12-yr cardiovascular mortality for men screened in the multiple risk factor intervention trial. Diabetes Care, 16, 434-444. http://dx.doi.org/10.2337/diacare.16.2.434

[2] Giugliano, D., Marfella, R., Coppola, I., Verrazzo, G., Acampora, R., Giunta, R., Nappo, F., Lucarelli, C.D. and Onofrio, F. (1997) Vascular effects of acute hyperglycemia in humans are reversed by L-arginine evidence for reduced availability of nitric oxide during hyperglycemia. Circulation, 95, 1783-1790. http://dx.doi.org/10.1161/01.CIR.95.7.1783

[3] Garcia, M.J., McNamara, P.M., Gordon, T. and Kannell, W.B. (1974) Morbidity and mortality in diabetes in the Framingham population, sixteen-year follow-up study. Diabetes, 23, 105-111.

[4] Jarrett, R.J. (1989) Cardiovascular disease and hypertension in diabetes mellitus. Diabetes/Meta Res and Rev, 5, 547-558.

[5] Ceriello, A. (2005) Postprandial hyperglycemia and diabetes complications. Is it time to treat? Diabetes, $\mathbf{5 4}, \mathbf{1 - 7}$. http://dx.doi.org/10.2337/diabetes.54.1.1

[6] Jorgensen, R.G., Russo, I., Marttioli, I. and Moore, W.V. (1988) Early detection of vascular dysfunction in Type I diabetes. Diabetes, 37, 292-296.

http://dx.doi.org/10.2337/diab.37.3.292

[7] Marfella, R., Verrazzo, G., Acampora, R., La Marca, C., Giunta, R., Lucarelli, C., Paolisso, G., Ceriello, A. and Giugliano, D. (1995) Glutathion reverses systemic hemodynamic change by acute hyperglycemia in healty subjects. American Journal of Physiology, 268, E1167-E1173.

[8] Witness, D.H. and Ojewole, J. (2008) Biphasic effect of Psidium guajava Linn. (Myrtaceae) leaf aqueous extract on rat isolated vascular smooth muscles. Journal of Smooth Muscle Research, 44, 217-229. http://dx.doi.org/10.1540/jsmr.44.217

[9] Mansoori Bahrani, A.H., Zaheri, H., Soltani, N., Kharazmi, F., Keshavarz, M. and Kamalinajad, M. (2012) Effect 
of the administration of Psidium guajave leaves on lipid profiles and sensitivity of the vascular mesenteric bed to phenylephrine in STZ-induced diabetic rats. Journal of Diabetes Mellitus, 2, 138-145.

http://dx.doi.org/10.4236/jdm.2012.21023

[10] Chiwororo, D.H. and Ojewole, J. (2008) Biphasic effect of psidium guajava Linn. (Myrtaceae) leaf aqueous extract on rat isolated vascular smooth muscle. Journal of Smooth Muscle Research, 44, 217-229. http://dx.doi.org/10.1540/jsmr.44.217

[11] Shen, S.C., Cheng, F.C. and Wu, N.J. (2008) Effect of Guava (Psidium guajava Linn.) leaf soluble solids on glucose metabolism in Type 2 diabetic rats. Phytotherapy Research, 22, 1458-1464. http://dx.doi.org/10.1002/ptr.2476

[12] McGregor, D.D. (1965) The effect of sympathetic nerve stimulation of vasoconstrictor responses in perfused mesenteric blood vessels of the rat. The Journal of Physiology, 177, 21-30.

[13] Wagner, A., Varga, K., Jarai, Z. and Kunos, G. (1999) Mesenteric vasodilation mediated by endothelium anandamide receptors. Hypertension, 33, 429-434. http://dx.doi.org/10.1161/01.HYP.33.1.429

[14] Ozcelikay, A.T., Tay, A., Guner, S., Tasyaran, V., Yildizoglu-Ar, N., Dincer, U.D. and Altan, V.M. (2000) Reversal effects of L-arginine treatment on blood pressure and vascular responsiveness of streptozotocin-diabetic rats. Pharmacological Research, 41, 201-209. http://dx.doi.org/10.1006/phrs.1999.0576

[15] Farsi, L., Keshavarz, M. and Soltani, N. (20101) Relaxatory effect of GABA mediated by same pathway in diabetic and normal rat vessel. Iranian Journal of Basic Medical Sciences, 4, 94-98.

[16] Soltani, N., Keshavarz, M., Sohanaki, H., Zahed Asl, S. and Dehpour, A.R. (2005) Relaxatory effect of magnesium on mesenteric vascular beds differs from normal and streptozotocin induced diabetic rats. European Journal of Pharmacology, 508, 177-181. http://dx.doi.org/10.1016/j.ejphar.2004.12.003

[17] Malmasjo, M., Edvinsson, L. and Erlingo, D. (1998)
P2U-receptor mediated endothelium-dependent but nitric oxide-independent vascular relaxation. British Journal of Pharmacology, 123, 719-729. http://dx.doi.org/10.1038/sj.bjp.0701660

[18] Laight, D.W., Carrier, M.J. and Anggard, E.E. (2000) Antioxidant, diabetes and endothelial dysfunction. Cardiovascular Research, 47, 457-464. http://dx.doi.org/10.1016/S0008-6363(00)00054-7

[19] Diederich, D., Skopec, J., Diederich, A. and Dai, F.X. (1994) Endothelial dysfunction in mesenteric resistance arteries of diabetic rat: Role of free radical. American Journal of Physiology, 266, H1153-H1161.

[20] Olatunji-Bello, I., Odusanya, A.J., Raji, I. and Ladipo, C.O. (2007) Contractile effect of aqueous extract of Psidium guajava leaves on aortic rings in rat. Fitoterapia, 78, 241-243. http://dx.doi.org/10.1016/j.fitote.2006.11.007

[21] Ajay, M., Achike, F.I., Mustafa, A.M. and Mustafa, M.R. (2006) Effect of quercetin on altered vascular reactivity in aorta isolated from sterptozotocin-induced diabetic rats. Diabetes Research and Clinical Practice, 73, 1-7. http://dx.doi.org/10.1016/j.diabres.2005.11.004

[22] Rasmussen, H., Takuwa, Y. and Park, S. (1987) Protein kinase $\mathrm{C}$ in the regulation of smooth muscle contraction. The FASEB Journal, 1, 177-185.

[23] Ferriola, P.C. and Cody, V. (1989) Middleton EJR Protein kinase $\mathrm{C}$ inhibition by flavonoids. Kinetic mechanism and structure-activity relationships. Biochemical Pharmacology, 38, 1617-1624. http://dx.doi.org/10.1016/0006-2952(89)90309-2

[24] Duarte, J., Perez-Vizcaino, F., Jimenez, J., Tamargo, J. and Zarzuelo, A. (1993) Vasodilatory effects of flavonoids in rat aortic smooth muscle. Structure-activity relationships. General Pharmacology, 24, 857-862. http://dx.doi.org/10.1016/0306-3623(93)90159-U

[25] Duarte, J., Perez-Vizcaino, F., Jimenez, J., Zarzuelo, A. and Tamargo, J. (1993) Vasodilator effects of quercetin on isolated rat vascular smooth muscle. European Journal of Pharmacology, 239, 1-7. http://dx.doi.org/10.1016/0014-2999(93)90968-N 